\title{
Perencanaan Pengembangan Aspek Teknis Operasional Dan Finansial Pengelolaan Sampah Kabupaten Mesuji
}

\author{
${ }^{1}$ Sulton Farid, ${ }^{2}$ Aleksander Purba \\ ${ }^{1}$ CV. RAZAKTHA \\ ${ }^{1}$ Jl. Cut Nyak Dien GG Sukajadi No 20 Kaliawi Tanjung Barat, Bandar Lampung 35115 \\ ${ }^{1}$ sulton.farid81@gmail. com
}

Intisari - Timbunan sampah di Kabupaten Mesuji dari tahun ke tahun mengalami peningkatan, karena aktivitas yang berasal dari perumahan, industri, perdagangan dan jasa, fasilitas kesehatan, pasar dan fasilitas umum. Bersamaan dengan kondisi lingkungan tersebut, adanya tuntutan MDGs yaitu memberikan pemenuhan layanan sanitasi lingkungan pada wilayah pemukiman, domestik dan industri, penanganan pelayanan persampahan menjadi salah satu bagian yang penting demi menuju lingkungan yang sehat dan bersih seperti yang diinginkan oleh sebagian masyarakat. Metode analisis yang digunakan adalah analisis kuantitatif dengan menghitung pengurangan, penanganan serta memproyeksikan sampah menggunakan indikator Peraturan Presiden Nomor 81 Tahun 2012 tentang Kebijakan dan Strategi Nasional Pengelolaan Sampah Rumah Tangga dan Sampah Sejenis Sampah Rumah Tangga. Hasil analisis data diketahui pada tahun 2030 timbulan sampah yaitu sebesar 28,04 ton/hari dengan pengurangan sampah ditargetkan mencapai $50 \%$. Agar pengelolaan menjadi lebih baik, dibutuhkan peningkatan kualitas pengurangan sampah dengan menambah sarana dan prasarana persampahan. Pada penanganan sampah dibutuhkan penambahan unit motor sampah, kontainer pasar, arm roll truk pasar, compactor truck, TPS 3R dan arm roll truk ke TPA. Estimasi biaya pengelolaan sampah dari TPS Ke TPA adalah sebesar Rp 587.028.141,-/m3/tahun. Estimasi besaran retribusi sampah yang didasarkan atas biaya operasional dan pelayanan untuk masing - masing kepala keluarga pada tahun 2030 adalah Rp. 4.203,-

Kata kunci - Aspek Teknis Operasional, Aspek Finansial, Pengelolaan Sampah

\section{PENDAHULUAN}

Kabupaten Mesuji merupakan salah satu wilayah yang sedang melaksanakan pembangunan di beberapa sektor. Pembangunan memang memberikan banyak sekali manfaat terutama penyediaan lapangan kerja bagi masyarakat, namun di sisi lain pembangunan juga membutuhkan pengorbanan-pengorbanan lingkungan seperti perubahan tata guna lahan, dari semula merupakan ruang hijau menjadi gedunggedung bertingkat atau permukiman, pertanian ataupun industri. Beberapa kegiatan tersebut akan menghasilkan residu berbentuk padat yang disebut sampah. Seperti hal nya di daerah lain, timbunan sampah di Kabupaten Mesuji dari tahun ke tahun mengalami peningkatan, karena aktivitas yang berasal dari perumahan, industri, perdagangan dan jasa, fasilitas kesehatan, pasar dan fasilitas umum (Master Plan Persampahan Kabupaten Mesuji, 2011).

Pertambahan penduduk dan perubahan pola konsumsi masyarakat ini juga dianggap sebagai faktor yang menyebabkan semakin tingginya jumlah sampah. Kondisi tersebut semakin parah apabila tingginya jumlah sampah yang dihasilkan tidak diimbangi dengan sistem penanganan yang tepat, sehingga permasalahan mengenai sampah menjadi permasalahan yang sulit diselesaikan.

Bersamaan dengan kondisi lingkungan tersebut, adanya tuntutan MDGs yaitu memberikan pemenuhan layanan sanitasi lingkungan pada wilayah pemukiman, domestik dan industri, penanganan pelayanan persampahan menjadi salah satu bagian yang penting demi menuju lingkungan yang sehat dan bersih seperti yang diinginkan oleh sebagian masyarakat.

Menurut Undang - Undang No. 18 tahun 2008 tentang Pengelolaan Sampah, pengelolaan sampah adalah kegiatan yang sistematis, menyeluruh dan berkesinambungan yang meliputi pengurangan dan penanganan sampah. Untuk meningkatkan kondisi pengelolaan persampahan secara keseluruhan di Kabupaten Mesuji, diperlukan suatu perencanaan yang memadai baik aspek teknik maupun manajemen. 


\section{TINJAUAN PUSTAKA}

Sampah ialah suatu bahan yang terbuang atau dibuang; merupakan hasil aktifitas manusia ataupun alam yang sudah tidak bias digunakan lagi karena sudah diambil unsur atau fungsi utamanya. Sumber sampah bisa berasal dari rumah tangga, pertanian, perkantoran, perusahaan, rumah sakit, pasar, dan sebagainya. Jumlah atau volume sampah sebanding dengan tingkat konsumsi terhadap barang/material yang digunakan sehari-sehari (Sejati, 2009).

Pengelolaan sampah dapat diartikan sebagai kegiatan yang menyeluruh dan berkesinambungan yang terdiri dari pengurangan dan penanganan sampah. Pengelolaan sampah bertujuan untuk meningkatkan kesehatan masyarakat dan kualitas lingkungan serta menjadikan sampah sebagai sumber daya (UU No 18 tahun 2008). Terdapat 5 (lima) aspek untuk menciptakan pengelolaan sampah yang baik yaitu, aspek teknik operasional, aspek kelembagaan, aspek hukum dan peraturan, aspek pembiayaan dan aspek peran serta masyarakat (SNI 19-24542002). Pengelolaan sampah adalah kegiatan yang sistematis dan berkesinambungan meliputi pengurangan sampah.

Teknik operasional pengelolaan sampah perkotaan meliputi dasar-dasar perencanaan untuk kegiatan : Perwadahan, Pengumpulan, Pemindahan, Pengangkutan, Pengolahan dan daur ulang, Pembuangan Akhir (Damanhuri dan Padmi, 2010).

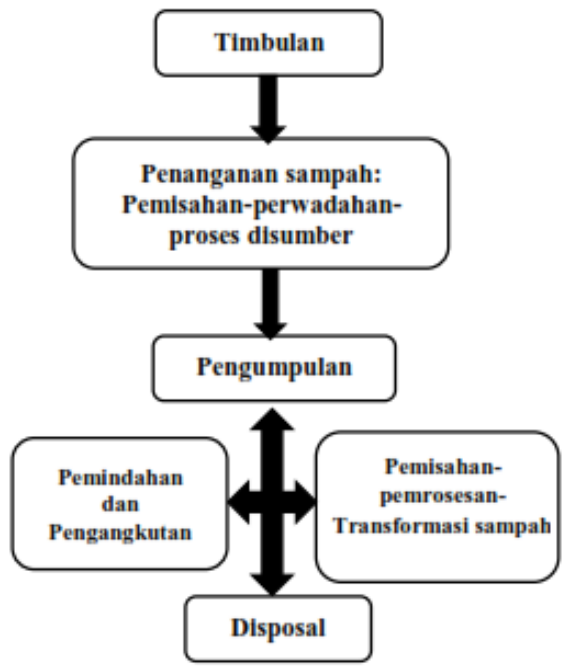

Gbr 1. Skema Teknik Operasional Pengelolaan Sampah

\section{METODE}

Pelaksanaan Perencanaan Pengelolaan Sampah di Kabupaten Mesuji ini dilaksanakan melaui beberapa tahapan, diantaranya tahap persiapan, pengumpulan data, kompilasi dan pengolahan data, analisis data lapangan

Bahan yang digunakan pada pengambilan data primer dan sekunder dalam penelitian ini yaitu timbulan sampah yang ada disetiap rumah tangga, Data luas lahan dan kependudukan bersumber dari Badan Pusat Statistik Kabupaten Mesuji dan Data Teknik Operasional dan Finansial dari Dinas Lingkungan Hidup Kabupaten Mesuji.

\section{Metode Pengumpulan Data \\ Data Sekunder}

Pengumpulan data sekunder dilakukan dengan menggunakan data yang ada baik dari hasil studi yang berkaitan dengan perencanaan sampah (RTRW, land use, Air Bersih, dll), kebijakan dan renstra daerah, hasil penelitian (seperti komposisi/karakteristik sampah, timbulan sampah, topografi, penyelidikaan tanah, dll), BPS (jumlah penduduk, pendapatan masyarakat, dll), maupun NSPM persampahan.

\section{Data Primer}

Data primer juga sangat dibutuhkan dalam penelitian ini. Data primer merupakan data yang diperoleh secara langsung dari lapangan atau sumber yang sebenarnya yang diantaranya pengambilan dan pengukuran sampel timbulan sampah pada beberapa rumah tangga atau KK di Kabupaten Mesuji.

\section{Proyeksi Laju Timbulan Sampah}

Perhitungan Proyeksi Timbulan Sampah Kabupaten Mesuji di dapatkan berdasarkan perhitungan proyeksi penduduk, maka dapat diketahui timbulan sampah penduduk di Kota Ternate rata-rata per hari pada tahun 2016 2030. Berikut adalah metode perhitungan laju timbulan sampah :

Timbulan Sampah

= Jumlah Sampah $x$ Jumlah Penduduk (Jiwa) 
Tabel 1. Klaisfikasi Wilayah Berdasarkan Timbulan Sampah

\begin{tabular}{|l|c|c|}
\hline $\begin{array}{c}\text { Klasifikasi } \\
\text { Wilayah }\end{array}$ & $\begin{array}{c}\text { Besaran } \\
\text { Timbulan } \\
\text { Sampah } \\
\text { (l/o/hr) }\end{array}$ & $\begin{array}{c}\text { Besaran } \\
\text { Timbulan } \\
\text { Sampah } \\
\text { (kg/o/hr) }\end{array}$ \\
\hline Metropolitan & - & - \\
\hline Besar & $2-2,5$ & $0,4-0,5$ \\
\hline Sedang/Kecil & $1,5-2$ & $, 0,3-0,4$ \\
\hline
\end{tabular}

\section{Metode Analisis Data}

Analisis data dilakukan dengan cara mengevaluasi kondisi eksisting secara kuantitatif menggunakan indikator Peraturan Presiden Nomor 81 Tahun 2012 tentang Kebijakan dan Strategi Nasional Pengelolaan Sampah Rumah Tangga dan Sampah Sejenis Rumah Tangga. Analisis tersebut akan menghasilkan tingkat pencapaian kinerja pengelolaan sampah Kabupaten Mesuji pada tahun 2016. Setelah itu, melakukan perencanaan pengelolaan sampah dalam 15 tahun ke depan.

\section{Tahapan Pelaksanaan}

Pelaksanaan kegiatan ini memiliki beberapa tahapan seperti gambar 2 .

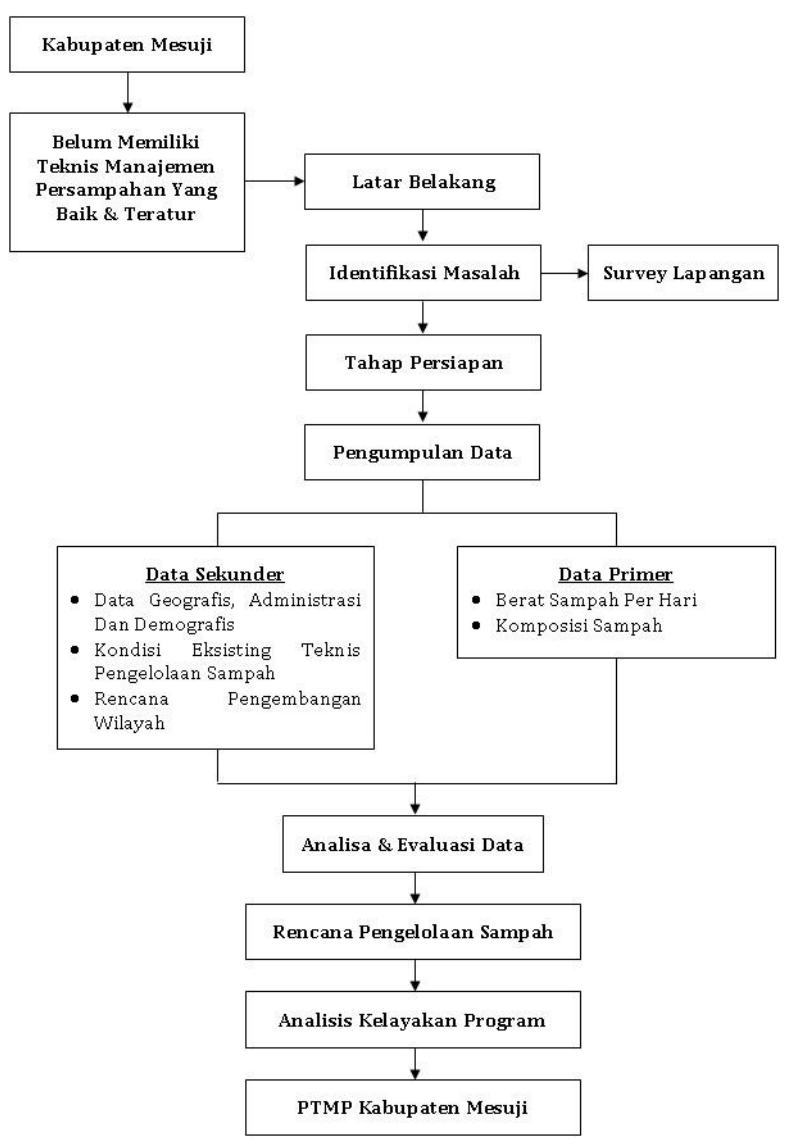

Gbr 2. Tahapan Pelaksanaan Perencanaan Pengelolaan Sampah Kabupaten Mesuji

\section{ANALISIS DAN PEMBAHASAN}

Berdasarkan data statistik yang tercatat oleh BPS, Jumlah Penduduk tahun 2015, Jumlah penduduk Kabupaten Mesuji mencapai 196.913 Jiwa. Dengan luas wilayah pada tahun tersebut sebesar $2.184 \mathrm{~km} 2$ berarti kepadatan penduduknya mencapai 90,16 jiwa per km2.

Berdasarkan data sensus penduduk yang dilakukan BPS RI, dapat diketahui jumlah penduduk pada masing - masing kecamatan yang ada di Kabupaten Mesuji berdasarkan klasifikasi wilayah tersebut. Dalam Peraturan Kepala BPS No. 37 Tahun 2010 yang berisi tentang klasifikasi perkotaan dan pedesaan atas desa/kelurahan di Kabupaten Mesuji.

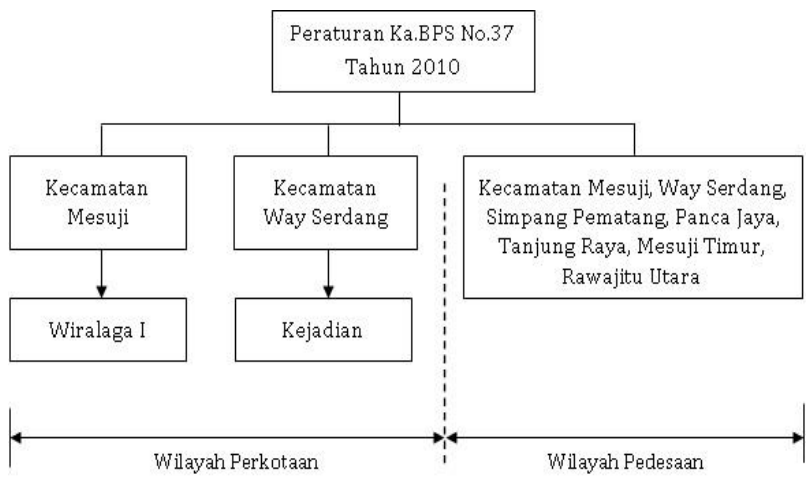

Gbr 3. Klasifikasi Wilayah Perkoaan/Pedesaan Di Kabupaten Mesuji

\section{Kondisi Eksisting Pengelolaan Sampah}

Penanganan sampah di wilayah Kabupaten Mesuji masih dilakukan secara individual oleh penduduk di Kabupaten Mesuji. Pelayanan persampahan di Kabupaten Mesuji baru menjangkau sampah beberapa pasar dengan pengelolaan oleh BPLH Kabupaten Mesuji.

Secara umum, penanganan sampah di Kabupaten Mesuji masih menggunakan sistem - angkut - buang. Belum terlihat adanya pemilahan atau pengolahan sampah baik di sumber atau di TPA. Penanganan sampah di Kabupaten Mesuji berbeda - beda sesuai dengan sumber sampahnya. $\mathrm{K}$

Secara khusus diperlukan TPS mengingat pada wilayah ini terdapat berbagai kegiatan yang menghasilkan limbah padat (sampah) yang perlu dikelola secara baik untuk menciptakan kawasan perkotaan yang memiliki daya tarik untuk berinvestasi. 


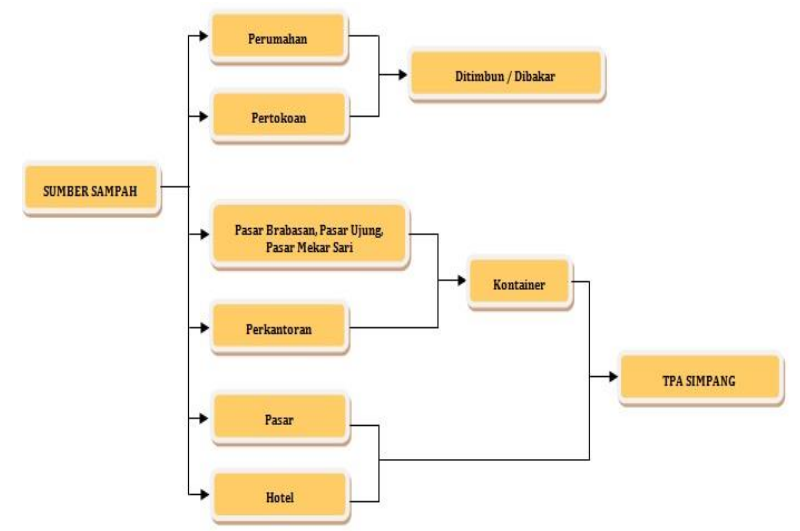

Gbr 4. Kondisi Eksisting Sistem Pengelolaan Sampah Di Kabupaten Mesuji

\section{Timbulan Dan Komposisi Sampah}

Timbulan sampah pada dasarnya sangat ditentukan oleh seluruh aktifitas yang menghasilkan sampah. Pengukuran timbulan dan komposisi sampah dilakukan terhadap beberapa lokasi pengambilan sampel sesuai sumber sampah, yaitu perumahan, pasar dan hotel. Pengukuran dilakukan untuk mengetahui timbulan sampah rata - rata yang bersumber dari kegiatan sehari - hari masyarakat di Kabupaten Mesuji.

Tabel 2. Berat Sampah Per Hari

\begin{tabular}{|c|c|c|c|c|}
\hline \multirow{2}{*}{$\begin{array}{l}\mathbf{N} \\
\mathbf{0}\end{array}$} & \multirow{2}{*}{$\begin{array}{l}\text { Sumber } \\
\text { Sampah }\end{array}$} & \multirow{2}{*}{$\begin{array}{c}\text { Satua } \\
\mathbf{n}\end{array}$} & \multicolumn{2}{|c|}{ Berat Sampah } \\
\hline & & & $\begin{array}{c}\text { kg/o/ } \\
\text { hr }\end{array}$ & $\begin{array}{c}\text { ton/o/h } \\
\mathbf{r}\end{array}$ \\
\hline 1 & Perumahan & $/ \mathrm{o} / \mathrm{hr}$ & 0,123 & $\begin{array}{c}0,0001 \\
23\end{array}$ \\
\hline 2 & Hotel & $/ \mathrm{o} / \mathrm{hr}$ & 0,464 & $\begin{array}{c}0,0004 \\
64\end{array}$ \\
\hline 3 & Pasar & $/ \mathrm{m}^{2} / \mathrm{hr}$ & 0,023 & $\begin{array}{c}0,0000 \\
23\end{array}$ \\
\hline 4 & Pertokoan & $/ \mathrm{o} / \mathrm{hr}$ & 0,521 & $\begin{array}{c}0,0005 \\
21\end{array}$ \\
\hline
\end{tabular}

Sampel yang sudah diukur tersebut kemudian dipilah untuk diketahui komposisinya. Pemilahan dilakukan berdasarkan jenis - jenis komposisi yang diketahui antara lain sampah organik, sampah palstik, sampah kaca dan sampah kertas.

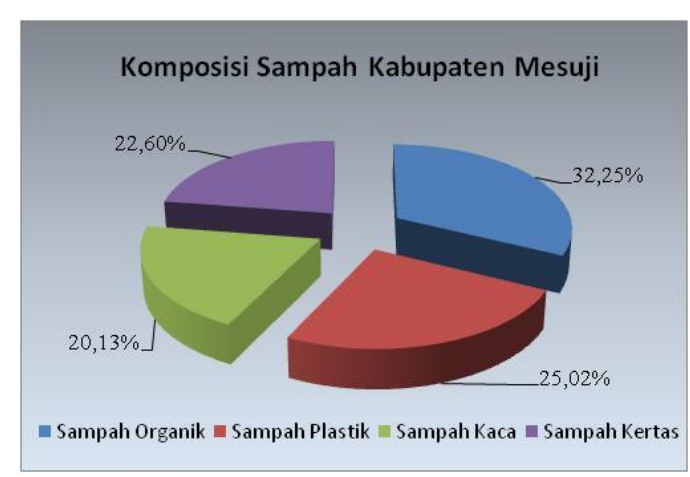

Gbr 5. Komposisi Sampah Kabupaten Mesuji

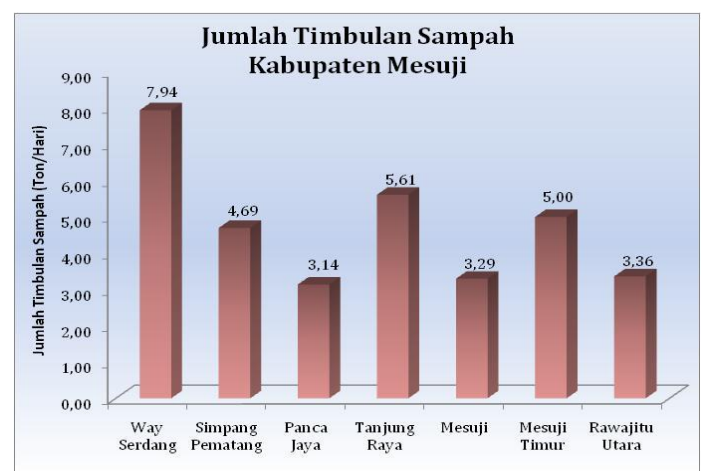

Gbr 6. Jumlah Timbulan Sampah Kabupaten Mesuji

\section{Evaluasi Kondisi Eksisting}

Berdasarkan hasil survey, diidentifikasi beberapa permasalahan yang ada di Kabupaten Mesuji terkait kondisi eksisting pengelolaan sampah. Beberapa permasalahan pengelolaan persampahan di Kabupaten Mesuji dikategorikan ke dalam beberapa bagian seperti berikut :

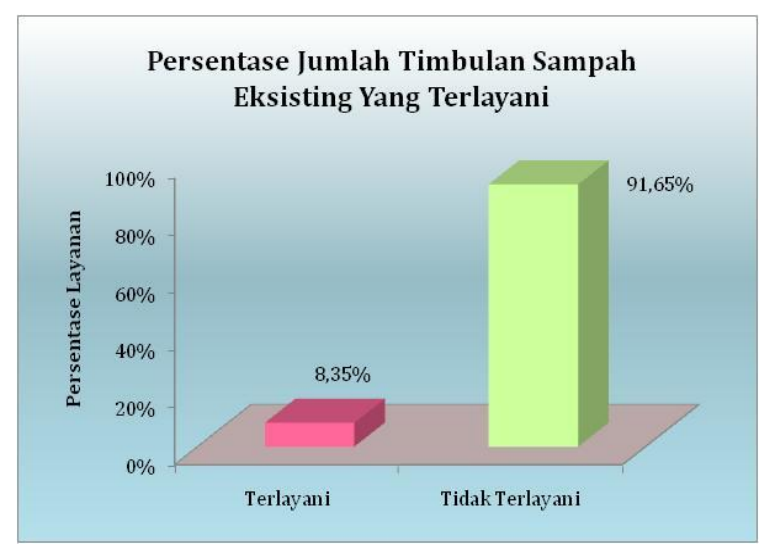

Gbr 7. Grafik Persentase Jumlah Timbulan Sampah Eksisting Yang Terlayani 
Tabel 3. Sampah Eksisting Yang Terangkut Ke

\begin{tabular}{|c|c|c|c|c|}
\hline \multirow{3}{*}{$\begin{array}{l}\mathbf{N} \\
\mathbf{0}\end{array}$} & \multirow{3}{*}{ Lokasi } & & & \\
\hline & & \multicolumn{3}{|c|}{$\begin{array}{c}\text { Jumlah Total Volume } \\
\text { Sampah }\end{array}$} \\
\hline & & $\begin{array}{l}\text { (Ton/ } \\
\text { Hari) }\end{array}$ & $\begin{array}{c}\text { (Ton/B } \\
\text { ulan) }\end{array}$ & $\begin{array}{l}\text { Ton/T } \\
\text { ahun) }\end{array}$ \\
\hline 1 & $\begin{array}{l}\text { Pasar } \\
\text { Simpang } \\
\text { Pematang }\end{array}$ & 0,69 & 20,7 & 248,4 \\
\hline 2 & Perkantoran & 0,31 & 1,24 & 14,88 \\
\hline 3 & $\begin{array}{l}\text { Pasar } \\
\text { Hadimulyo }\end{array}$ & 0,46 & 1,84 & 22,08 \\
\hline 4 & $\begin{array}{l}\text { Pasar Ujung } \\
\text { Buring }\end{array}$ & 0,31 & 1,24 & 14,88 \\
\hline 5 & $\begin{array}{l}\text { Pasar Panca } \\
\text { Warna }\end{array}$ & 0,58 & 2,32 & 27,84 \\
\hline 6 & $\begin{array}{l}\text { Pasar Harapan } \\
\text { Mukti }\end{array}$ & 0,23 & 0,92 & 11,04 \\
\hline 7 & $\begin{array}{l}\text { Pasar Gedung } \\
\text { Ram }\end{array}$ & 0,23 & 0,92 & 11,04 \\
\hline & Jumlah & 2,81 & 22,48 & 269,8 \\
\hline
\end{tabular}

Berdasarkan hasil survey, diidentifikasi beberapa permasalahan yang ada di TPA Simpang Pematang Kabupaten Mesuji, yaitu :

1) Tidak berfungsinya bangunan kantor dan hanggar karena tidak adanya jaringan listrik dan kendaraan pengangkut sampah di TPA.

2) Tidak teraturnya cara pembuangan sampah mengakibatkan tidak teraturnya area landfill.

3) Tidak tersedia alat berat sehingga pengerukan sampah masih dilakukan dengan cara manual.

Tabel 4. Kapasitas Daya Tampung TPA Mesuji

\begin{tabular}{|c|c|c|c|c|c|}
\hline \multirow[b]{2}{*}{$\begin{array}{l}\mathbf{N} \\
\text { o. }\end{array}$} & \multirow{2}{*}{$\begin{array}{l}\text { Tah } \\
\text { un }\end{array}$} & \multirow{2}{*}{$\begin{array}{c}\text { Beban } \\
\text { Operasi } \\
\text { onal } \\
\left(\mathbf{m}^{3} / \mathbf{h r}\right)\end{array}$} & \multicolumn{2}{|c|}{$\begin{array}{c}\text { Beban Sampah } \\
\text { Di TPA } \\
\end{array}$} & \multirow{2}{*}{$\begin{array}{c}\text { Sisa } \\
\text { Kapas } \\
\text { itas } \\
\text { Tamp } \\
\text { ung } \\
\left(\mathbf{m}^{3}\right)\end{array}$} \\
\hline & & & $\begin{array}{c}\mathbf{m}^{3} / \mathbf{h a} \\
\mathbf{~ r i}\end{array}$ & $\underset{\mathbf{n}}{\mathbf{m}^{3} / \text { tahu }}$ & \\
\hline 1 & $\begin{array}{c}201 \\
5\end{array}$ & 698,76 & $\begin{array}{c}399,2 \\
9\end{array}$ & $\begin{array}{c}143.745, \\
83\end{array}$ & $\begin{array}{c}33.374 \\
, 17\end{array}$ \\
\hline 2 & $\begin{array}{c}201 \\
6\end{array}$ & 706,23 & $\begin{array}{c}403,5 \\
6 \\
\end{array}$ & $\begin{array}{c}145.280, \\
95\end{array}$ & $\begin{array}{c}31.839 \\
, 05 \\
\end{array}$ \\
\hline 3 & $\begin{array}{c}201 \\
7\end{array}$ & 713,77 & $\begin{array}{c}407,8 \\
7\end{array}$ & $\begin{array}{c}146.832, \\
37\end{array}$ & $\begin{array}{c}30.287 \\
, 63\end{array}$ \\
\hline 4 & $\begin{array}{c}201 \\
8\end{array}$ & 721,39 & $\begin{array}{c}412,2 \\
2\end{array}$ & $\begin{array}{c}148.400, \\
39\end{array}$ & $\begin{array}{c}28.719 \\
, 61 \\
\end{array}$ \\
\hline 5 & $\begin{array}{c}201 \\
9\end{array}$ & 729,09 & $\begin{array}{c}416,6 \\
3\end{array}$ & $\begin{array}{c}149.985, \\
19\end{array}$ & $\begin{array}{c}27.134 \\
, 81\end{array}$ \\
\hline 6 & $\begin{array}{c}202 \\
0\end{array}$ & 736,88 & $\begin{array}{c}421,0 \\
7\end{array}$ & $\begin{array}{l}151.586, \\
95\end{array}$ & $\begin{array}{c}25.533 \\
, 05\end{array}$ \\
\hline 7 & $\begin{array}{c}202 \\
1\end{array}$ & 744,75 & $\begin{array}{c}425,5 \\
7\end{array}$ & $\begin{array}{c}153.205 \\
84\end{array}$ & $\begin{array}{c}23.914 \\
, 16 \\
\end{array}$ \\
\hline
\end{tabular}

\begin{tabular}{|c|c|c|c|c|c|}
8 & $\begin{array}{c}202 \\
2\end{array}$ & 752,70 & $\begin{array}{c}430,1 \\
2\end{array}$ & $\begin{array}{c}154.842, \\
06\end{array}$ & $\begin{array}{c}22.277 \\
, 94\end{array}$ \\
\hline 9 & $\begin{array}{c}202 \\
3\end{array}$ & 760,74 & $\begin{array}{c}434,7 \\
1\end{array}$ & $\begin{array}{c}156.495, \\
79\end{array}$ & $\begin{array}{c}20.624 \\
, 21\end{array}$ \\
\hline 10 & $\begin{array}{c}202 \\
4\end{array}$ & 768,87 & $\begin{array}{c}439,3 \\
5\end{array}$ & $\begin{array}{c}158.167, \\
21\end{array}$ & $\begin{array}{c}18.952 \\
, 79\end{array}$ \\
\hline 11 & $\begin{array}{c}202 \\
5\end{array}$ & 777,08 & $\begin{array}{c}444,0 \\
5\end{array}$ & $\begin{array}{c}159.856, \\
51\end{array}$ & $\begin{array}{c}17.263 \\
49\end{array}$ \\
\hline 12 & $\begin{array}{c}202 \\
6\end{array}$ & 785,38 & $\begin{array}{c}448,7 \\
9\end{array}$ & $\begin{array}{c}161.563, \\
89\end{array}$ & $\begin{array}{c}15.556 \\
, 11\end{array}$ \\
\hline 13 & $\begin{array}{c}202 \\
7\end{array}$ & 793,77 & $\begin{array}{c}453,5 \\
8\end{array}$ & $\begin{array}{c}163.289, \\
54\end{array}$ & $\begin{array}{c}13.830 \\
46\end{array}$ \\
\hline 14 & $\begin{array}{c}202 \\
8\end{array}$ & 802,25 & $\begin{array}{c}458,4 \\
3\end{array}$ & $\begin{array}{c}165.033, \\
66\end{array}$ & $\begin{array}{c}12.086 \\
, 34\end{array}$ \\
\hline 15 & $\begin{array}{c}202 \\
9\end{array}$ & 810,82 & $\begin{array}{c}463,3 \\
2\end{array}$ & $\begin{array}{c}166.796, \\
43\end{array}$ & $\begin{array}{c}10.323 \\
, 57\end{array}$ \\
\hline 16 & $\begin{array}{c}203 \\
0\end{array}$ & 819,48 & $\begin{array}{c}468,2 \\
7\end{array}$ & $\begin{array}{c}168.578, \\
07\end{array}$ & $\begin{array}{c}8.541 \\
93\end{array}$ \\
\hline
\end{tabular}

Selain pengolahan data, telah diadakan juga evaluasi lahan TPA yang memperhitungan beberapa variabel, dan hasilnya adalah TPA Kabupaten Mesuji masih berada dalam status bahaya ringan dan masih dapat dioperasikan dengan baik.

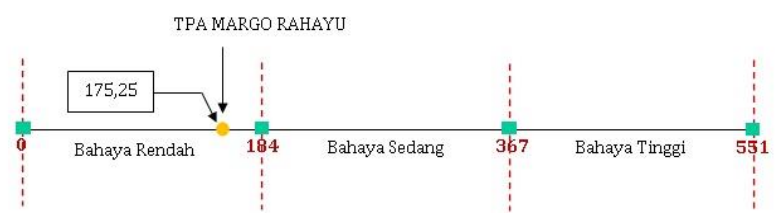

Gbr 8. Evaluasi Resiko Bahaya Lahan TPA Kabupaten Mesuji

Daerah pelayanan persampahan Kabupaten Mesuji meliputi 4 Kecamatan yaitu Kecamatan Simpang Pematang, Kecamatan Tanjung Jaya, Kecamatan Mesuji dan Kecamatan Mesuji Timur. Namun, berdasarkan hasil survey, pelayanan persampahan untuk 4 kecamatan tersebut hanya meliputi daerah pasar dan perkantoran. Sampai saat ini wilayah yang masuk dalam cakupan pelayanan baru mencapai $6,3 \%$ dari seluruh wilayah yang ada di Kabupaten Mesuji.

Daerah pelayanan persampahan di Kabupaten Mesuji baru sebatas sekitar Ibu Kota Kabupaten Mesuji, sumber sampah berasal dari sebagian pasar dan perkantoran di sekitar instansi Pemerintahan. Sampah yang terkumpul ini meliputi sampah yang berasal dari daerah - daerah yang dapat dijangkau oleh motor dan truk pengangkut sampah, belum mencapai semua wilayah desa. 


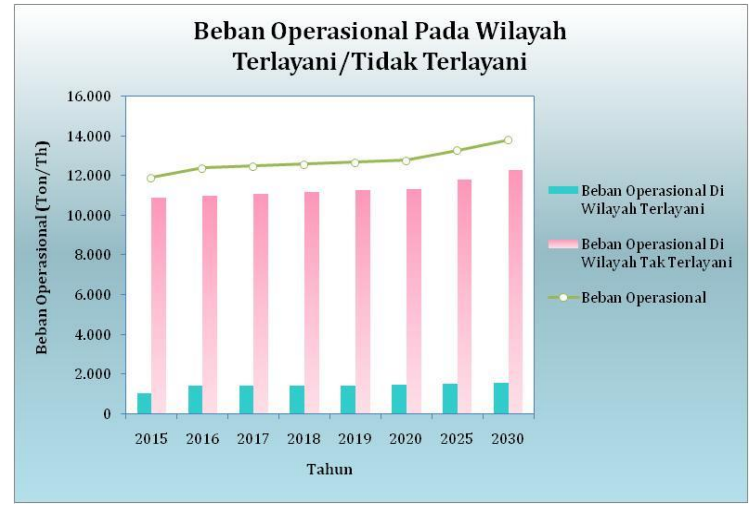

Gbr 9. Grafik Beban Operasional Pada Wilayah Terlayani/Tidak Terlayani

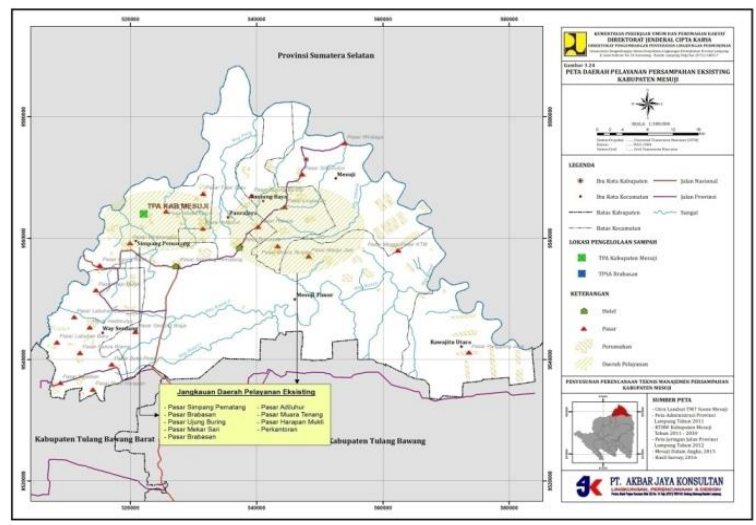

Gbr 10. Peta Pelayanan Persampahan Eksisting

\section{Perencanaan Pengurangan Dan Penangananan Sampah}

Prioritas utama yang harus dilakukan oleh semua pihak adalah bagaimana agar mengurangi sampah semaksimal mungkin. Bagian sampah atau residu dari kegiatan pengurangan sampah yang masih tersisa selanjutnya dilakukan pengolahan maupun pengurangan. Pengurangan sampah melalui 3 R meliputi :

1) Pembatasan (reduce), yaitu mengupayakan agar sampah yang dihasilkan sesedikit mungkin.

2) Guna Ulang (reuse), yaitu bila sampah akhirnya terbentuk, maka upayakan memanfaatkan sampah tersebut secara langsung.

3) Daur Ulang (recycle), yaitu memanfaatkan residu yang tersisa atau tidak dapat dimanfaatkan baik sebagai bahan baku maupun sebagai sumber energi.

Dalam perencanaan pengelolaan persampahan Kabupaten Mesuji periode tahun 2015 - 2030 akan dilakukan beberapa tahapan, antara lain :
1) Periode tahun 2015 - 2020, diorientasikan sebagai pengenalan pemilahan kepada masyarakat umum dengan memasang wadah sampah terpilah di jalan protokol, taman kota, perkantoran, pariwisata, institusi pendidikan dan fasilitas umum lainnya.

2) Periode tahun 2021 - 2025, merupakan masa pengenalan yang lebih intensif dengan melakukan pembinaan di lingkungan pemukiman yang menjadi sasaran pengembangan sampah berbasis masyarakat. Dalam periode ini pula diterapkan mekanisme pemilahan yang sesuai dengan masyarakat di Kabupaten Mesuji dan penerapan pengelolaan sampah berbasis masyarakat.

3) Periode tahun 2026 - 2030, merupakan masa implementasi konsep pemilahan untuk menuju zero waste.

Tabel 5. Strategi Pengumpulan Sampah

\begin{tabular}{|c|c|}
\hline & \\
\hline $\begin{array}{l}\text { oulan } \\
\text { di pusat } \\
\text { di }\end{array}$ & 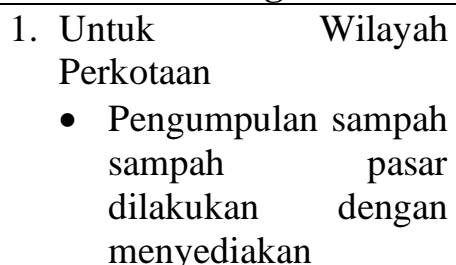 \\
\hline $\begin{array}{l}\text { sampah } \\
\text { k } \\
\text { awasan } \\
\text { lan }\end{array}$ & $\begin{array}{l}\text { kontainer pasar. } \\
\text { - Pengumpulan sampah } \\
\text { pemukiman, komersil } \\
\text { dan institusi dilayani } \\
\text { dengan sistem }\end{array}$ \\
\hline $\begin{array}{l}\text { di } \\
\text { n } \\
\text { man untuk } \\
\text { perkotaan } \\
\text { ilayani } \\
\text { rana } \\
\text { ipulan }\end{array}$ & $\begin{array}{l}\text { komunal langsung } \\
\text { dengan menggunakan } \\
\text { motor sampah untuk } \\
\text { dikumpulkan di TPS } \\
\text { 3R. } \\
\text { 2. Untuk Wilayah Pedesaan } \\
\text { - Pengumpulan sampah }\end{array}$ \\
\hline $\begin{array}{l}\text { Sampah di } \\
\text { kawasan } \\
\text { pemukiman untuk } \\
\text { wilayah pedesaan } \\
\text { dapat dikelola } \\
\text { oleh kawasan } \\
\text { masing - masing }\end{array}$ & 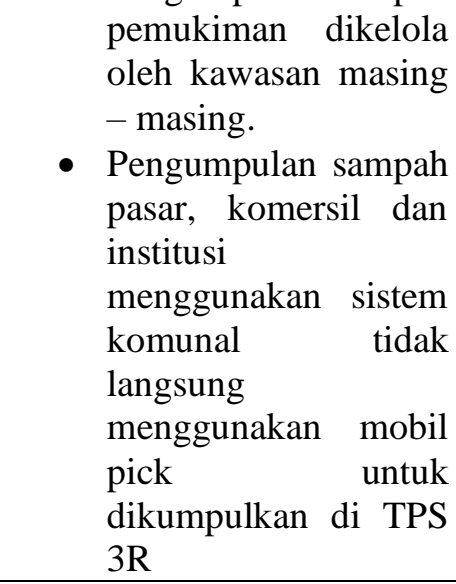 \\
\hline
\end{tabular}




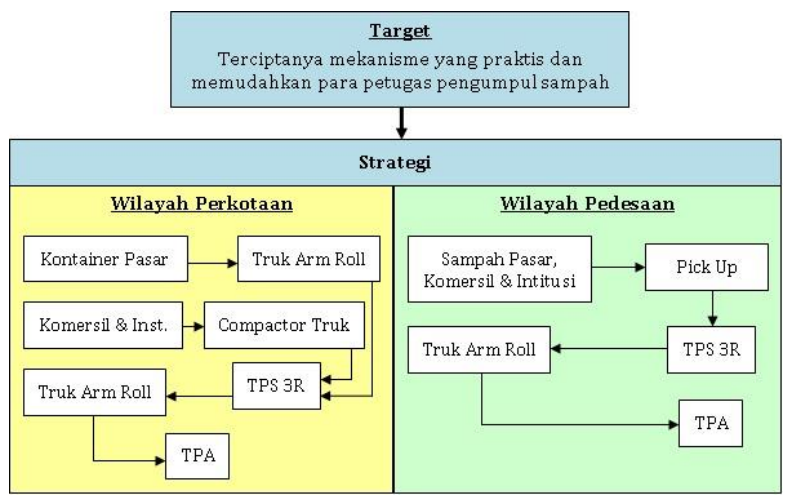

Gbr 11. Skema Target Dan Strategi Pengangkutan Sampah

\section{Pembagian Zona Pelayanan}

Pengelolaan persampahan di Kabupaten Mesuji direncanakan dibagi dalam 2 zona. Rencana pemilihan zona tersebut didasarkan pada beberapa paramater, antara lain :

1) Jumlah penduduk, jumlah ketersediaan pasar, pusat perbelanjaan, kawasan komersial, sarana kesehatan, institusi pendidikan dan beberapa kawasan lain yang dianggap penting untuk diidentifikasi timbulan sampah per harinya.

2) Pengembangan wilayah perkotaan dan perdesaan setempat

3) Kondisi dan akses sarana dan prasarana jalan dan transportasi yang ada.

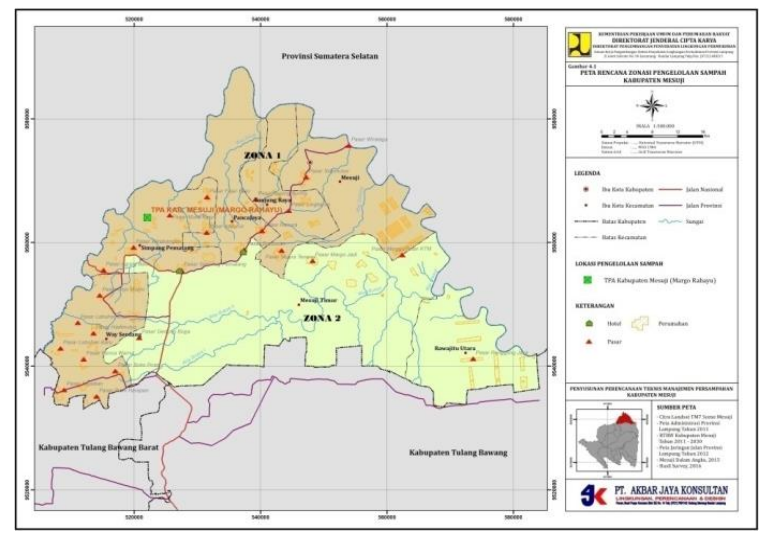

Gbr 12. Peta Zonasi Pengelolaan Sampah

Perencanaan zona 1 ini dilakukan dengan mengelompokkan Kecamatan Way Serdang, Kecamatan Simpang Pematang, Kecamatan Panca Jaya, Kecamatan Tanjung Raya dan Kecamatan Mesuji menjadi dalam satu zona pengelolaan sampah. Dengan dikelompokannya beberapa Kecamatan ini, lokasi pengelolaan sampah yang meliputi TPA dan rencana TPS berada pada satu lokasi. Zonasi ini dilakukan karena mempertimbangkan aspek lokasi yang diperkirakan memungkinkan untuk dijangkau oleh beberapa Kecamatan ini sehingga dapat memudahkan proses pengangkutan dan pemindahan.

Zona 2 ini terdiri dari 2 (dua) kecamatan yang ada di Kabupaten Mesuji. Zona 2 ini memiliki luas 1.067,44 km2 dengan jumlah penduduk 28,5\% dari jumlah penduduk Kabupaten Mesuji.

\section{Pembagian Zona Prioritas}

Perhitungan penetuan wilayah prioritas didasarkan atas penilaian dari beberapa parameter yang dilakukan dengan metode skoring. Hasil perhitungan tersebut dapat dilihat pada tabel Zona Prioritas Persampahan Kabupaten Mesuji.

Tabel 6. Parameter Penentuan Skala Prioritas Pelayanan

\begin{tabular}{|c|c|c|}
\hline No & Parameter & $\begin{array}{c}\text { Bob } \\
\text { ot }\end{array}$ \\
\hline \multirow{4}{*}{1} & Fungsi Dan Nilai Daerah & \multirow{4}{*}{3} \\
\hline & a. Daerah protokol/pusat kota & \\
\hline & b. Daerah komersial & \\
\hline & $\begin{array}{l}\text { c. Daerah rencana pengembangan } \\
\text { RTRW }\end{array}$ & \\
\hline 2 & Daerah Pelayanan Eksisting & 2 \\
\hline 3 & Tingkat Kepadatan Penduduk & 2 \\
\hline 4 & Timbulan Sampah Kota & 2 \\
\hline 5 & $\begin{array}{l}\text { Kondisi Lingkungan Dan } \\
\text { Kesehatan }\end{array}$ & 1 \\
\hline \multicolumn{2}{|r|}{ Jumlah } & 10 \\
\hline \multicolumn{3}{|c|}{$\begin{array}{l}\text { Keterangan } \\
- \text { - Skor } 7-10=\text { Prioritas I } \\
- \text { Skor } 4-6=\text { Prioritas II } \\
- \text { Skor } 1-3=\text { Prioritas III }\end{array}$} \\
\hline
\end{tabular}

Tabel 7. Zona Prioritas Pelayanan Persampahan

\begin{tabular}{|c|l|c|}
\hline No. & \multicolumn{1}{|c|}{ Kecamatan } & $\begin{array}{c}\text { Zona Pelayanan } \\
\text { Prioritas }\end{array}$ \\
\hline 1 & Way Serdang & I \\
\hline 2 & Simpang Pematang & II \\
\hline 3 & Panca Jaya & II \\
\hline 4 & Tanjung Raya & II \\
\hline 5 & Mesuji & I \\
\hline 6 & Mesuji Timur & III \\
\hline 7 & Rawajitu Utara & III \\
\hline
\end{tabular}

\section{Perhitungan Teknis Operasional Wilayah Prioritas Pelayanan 1}

Sarana dan prasarana yang diperlukan untuk mendukung pelaksnaaan pengelolaan 
sampah pada wilayah prioritas 1 ini antara lain

1) Alat pewadahan dengan kapasitas $0,05 \mathrm{~m} 3$.

2) Motor sampah kapasitas $1,5 \mathrm{~m} 3$ dengan ritasi 2 kali sehari untuk alat pengumpulan sampah pemukiman.

3) TPS 3R pada setiap kecamatan dengan fasilitas pemilahan, pencacahan dan daur ulang.

4) Kontainer pasar dengan kapsitas $8 \mathrm{~m} 3$.

5) Compactor truk untuk pengumpulan sampah komersil, intitusi pendidikan dan perkantoran.

6) Truk arm roll kapasitas $8 \mathrm{~m} 3$ dengan 2 kali ritasi sehari untuk alat pengangkutan sampah pasar ke TPS 3R dan dari TPS 3R ke TPA.

\section{Perhitungan Teknis Operasional Wilayah Prioritas Pelayanan $2 \& 3$}

Konsep pengelolaan sampah di wilayah prioritas pelayanan 2 dan 3 ini berpedoman kepada Tata Cara Penyelenggaraan Sistem Pengelolaan Sampah di Kawasan Pedesaan. Penanganan sampah yang terdiri dari pewadahan, pengumpulan/pengangkutan, pengolahan, dan pemrosesan akhir. Penanganan sampah di kawasan perdesaan dilakukan dengan cara sesederhana mungkin dengan mempertimbangkan kearifan lokal, artinya pemerintah daerah dapat menyesuaikan prasarana dan sarana pengelolaan sampah dengan menggunakan material yang tersedia di daerah tersebut.

Tabel 8. Kebutuhan Penambahan Sarana Dan Prasarana Persampahan Kabupaten Mesuji Jangka Pendek

\begin{tabular}{|l|c|c|c|c|}
\hline \multirow{2}{*}{$\begin{array}{c}\text { Sarana \& } \\
\text { Prasarana }\end{array}$} & \multicolumn{5}{|c|}{ Jangka Pendek } \\
\cline { 2 - 5 } & $\mathbf{2 0 1}$ & $\mathbf{2 0 1}$ & $\mathbf{2 0 1}$ & $\mathbf{2 0 2}$ \\
& $\mathbf{7}$ & $\mathbf{9}$ & $\mathbf{0}$ \\
\hline Zona Prioritas 1 & 22 & 7 & 54 & 51 \\
\hline Motor Sampah & 1 & 0 & 0 & 3 \\
\hline Kontainer Pasar & 2 & 0 & 0 & 0 \\
\hline Arm Roll Pasar & 1 & 2 & 0 & 0 \\
\hline Compactor Truk & 1 & 0 & 1 & 1 \\
\hline TPS 3R & 1 & 0 & 0 & 0 \\
\hline Arm Roll Ke TPA & \multicolumn{5}{|l}{} \\
\hline Zona Prioritas 2 & 0 & 0 & 0 & 0 \\
\hline Mobil Pick Up & 3 & 0 & 0 & 0 \\
\hline TPS 3R & 3 & 0 & 0 & 0 \\
\hline Arm Roll & \multicolumn{5}{|l}{} \\
\hline Zona Prioritas 3 & \multicolumn{5}{|l|}{} \\
\hline
\end{tabular}

\begin{tabular}{|l|l|l|l|l|} 
Mobil Pick Up & 1 & 0 & 0 & 0 \\
\hline TPS 3R & 2 & 0 & 0 & 0 \\
\hline Arm Roll & 2 & 0 & 0 & 0 \\
\hline
\end{tabular}

Tabel 9. Kebutuhan Penambahan Sarana Dan Prasarana Persampahan Kabupaten Mesuji Jangka Menengah

\begin{tabular}{|l|c|c|c|c|c|c|}
\hline \multirow{2}{*}{$\begin{array}{l}\text { Sarana \& } \\
\text { Prasarana }\end{array}$} & \begin{tabular}{c} 
Jangka Menengah \\
\cline { 2 - 6 }
\end{tabular} & $\mathbf{2 0 2}$ & $\mathbf{2 0 2}$ & $\mathbf{2 0 2}$ & $\mathbf{2 0 2}$ \\
\hline Zona Prioritas 1 & $\mathbf{4}$ & $\mathbf{5}$ & $\mathbf{5}$ \\
\hline Motor Sampah & 12 & 42 & 2 & 2 & 2 \\
\hline Kontainer Pasar & 0 & 1 & 0 & 0 & 0 \\
\hline Arm Roll Pasar & 0 & 0 & 0 & 0 & 0 \\
\hline Compactor Truk & 0 & 0 & 0 & 0 & 0 \\
\hline TPS 3R & 0 & 0 & 0 & 0 & 0 \\
\hline $\begin{array}{l}\text { Arm Roll Ke } \\
\text { TPA }\end{array}$ & 0 & 0 & 0 & 0 & 0 \\
\hline Zona Prioritas 2 \\
\hline Mobil Pick Up & 1 & 0 & 0 & 1 & 0 \\
\hline TPS 3R & 0 & 0 & 0 & 0 & 0 \\
\hline Arm Roll & 0 & 0 & 0 & 0 & 0 \\
\hline Zona Prioritas 3 & 0 & 0 & 0 & 0 & 0 \\
\hline Mobil Pick Up & 0 & 0 & 0 & 0 & 0 & 0 \\
\hline TPS 3R & 0 & 0 & 0 & 0 & 0 \\
\hline Arm Roll
\end{tabular}

Tabel 10. Kebutuhan Penambahan Sarana Dan Prasarana Persampahan Kabupaten Mesuji Jangka Panjang

\begin{tabular}{|l|c|c|c|c|c|}
\hline \multirow{2}{*}{$\begin{array}{l}\text { Sarana \& } \\
\text { Prasarana }\end{array}$} & $\begin{array}{c}\mathbf{5 0 2} \\
\text { 6 }\end{array}$ & $\mathbf{2 0 2}$ & $\mathbf{2 0 2}$ & $\mathbf{2 0 2}$ & $\mathbf{2 0 3}$ \\
$\mathbf{n y y y y}$ & $\mathbf{9}$ & $\mathbf{9}$ & $\mathbf{0}$ \\
\hline Zona Prioritas 1 \\
\hline Motor Sampah & 2 & 2 & 2 & 2 & 2 \\
\hline Kontainer Pasar & 0 & 0 & 0 & 0 & 0 \\
\hline Arm Roll Pasar & 0 & 0 & 0 & 0 & 0 \\
\hline Compactor Truk & 0 & 0 & 0 & 0 & 0 \\
\hline TPS 3R & 0 & 0 & 0 & 0 & 0 \\
\hline $\begin{array}{l}\text { Arm Roll Ke } \\
\text { TPA }\end{array}$ & 0 & 0 & 0 & 0 & 0 \\
\hline Zona Prioritas 2 \\
\hline Mobil Pick Up & 1 & 0 & 2 & 0 & 0 \\
\hline TPS 3R & 0 & 0 & 0 & 0 & 0 \\
\hline Arm Roll & 0 & 0 & 0 & 0 & 0 \\
\hline Zona Prioritas 3 & 1 & 0 & 2 & 0 & 0 \\
\hline Mobil Pick Up & 0 & 0 & 0 & 0 & 0 \\
\hline TPS 3R & 0 & 0 & 0 & 0 & 0 \\
\hline Arm Roll &
\end{tabular}




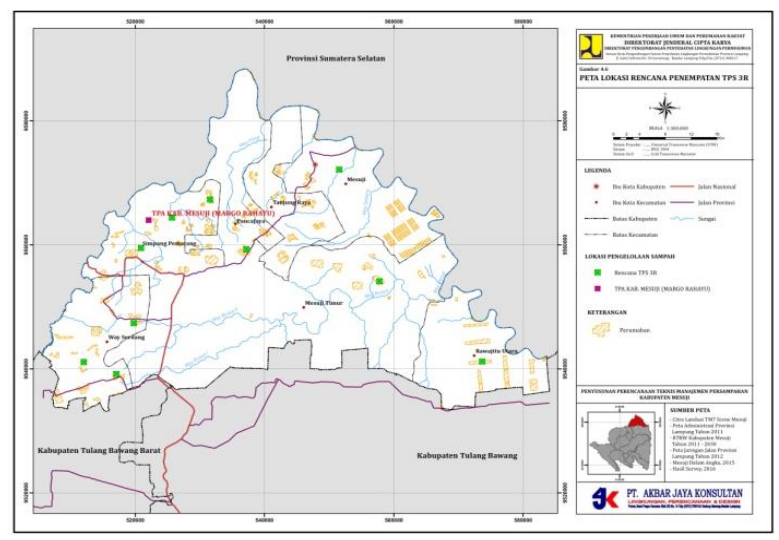

Gbr 13. Lokasi Rencana Penempatan TPS 3R

Dalam perencananaan pengelolaan persampahan Kabupaten Mesuji, akan dilakukan beberapa tahapan, antara lain :

1) Periode tahun 2016 - 2020 (jangka pendek), diorientasikan sebagai masa pengenalan yang lebih intensif dengan melakukan pembinaan di lingkungan pemukiman yang menjadi sasaran pengembangan sampah berbasis masyarakat. Dalam periode ini pula dicari bentuk dan mekanisme pemilihan yang dapat diterima sesuai dengan tatanan sosial budaya masyarakat di Kabupaten Mesuji.

2) Periode tahun 2021 - 2025 (Jangka Menengah), diharapkan sudah diterapkan mekanisme pemilahan yang sesuai dengan masyarakat dan implementasi dari pengelolaan sampah berbasis masyarakat seperti sudah beroperasinya TPST 3R.

3) Periode tahun 2026 - 2030 (Jangka Panjang), merupakan masa implementasi konsep pemilahan untuk menuju zero waste.

\section{Rencana Pembiayaan Investasi Program}

Kebutuhan investasi dalam pengelolaan sampah merupakan informasi yang sangat penting bagi para pengambil keputusan dalam rangka menyusun APBD setiap tahunnya. Adapun sarana yang diperhitungkan adalah seluruh item yang menjadi tanggung jawab Pemerintah dalam pengadaannya, yaitu :

1) Motor Sampah

2) Mobil Pick Up

3) Kontainer penampung sampah pasar
4) Truk Arm Roll untuk alat pengakutan sampah

5) Tempat pengolahan Sampah berbasis $3 R$ pada tiap kecamatan di Kabupaten Mesuji.

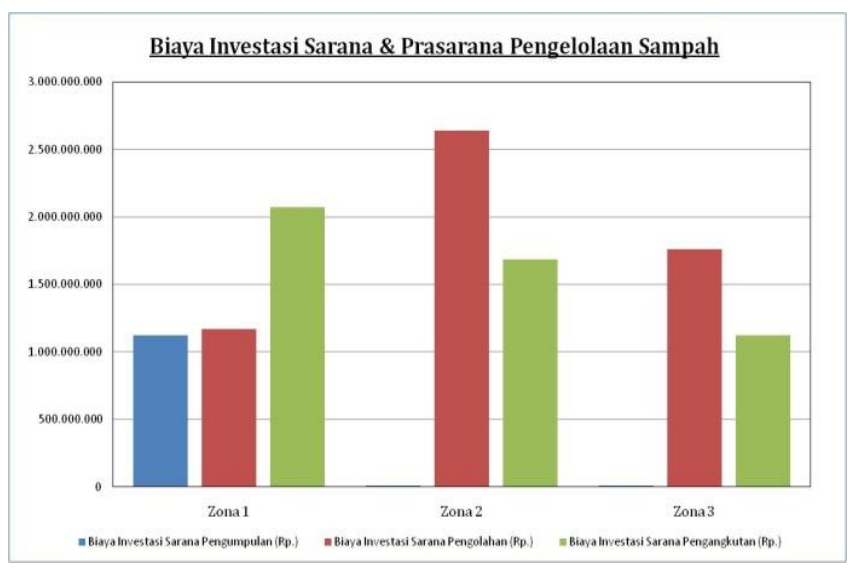

Gbr 14. Grafik Biaya Investasi Sarana \& Prasarana Persampahan

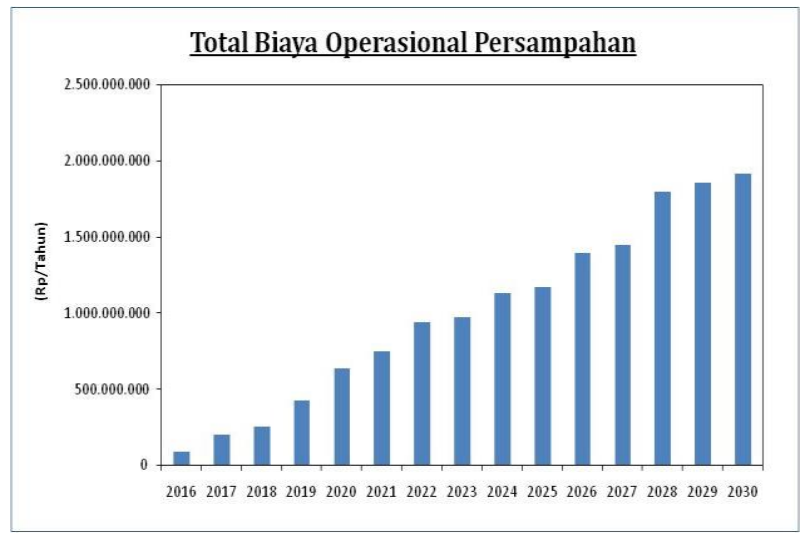

Gbr 15. Total Biaya Operasional Pengelolaan Sampah

Analisis biaya satuan ini dimaksudkan untuk mengetahui biaya operasional dan pemeliharaan yang dibutuhkan per satuan sampah yang dikelola (dalam hal ini per $\mathrm{m}^{3}$ ). Hal ini diperlukan untuk mengestimasi kebutuhan biaya operasional dan pemeliharaan (O\&M) seiring dengan peningkatan kapasitas pengelolaan. Oleh karena itu khusus untuk perhitungan biaya satuan pengelolaan sampah secara konvensional maka biaya yang dihitung hanya biaya yang langsung berhubungan dengan biaya pengelolaan sampah. 
Tabel 11. Biaya Operasional Pengelolaan Sampah

\begin{tabular}{|c|l|c|c|c|c|c|}
\hline $\begin{array}{c}\text { No } \\
.\end{array}$ & \multicolumn{1}{|c|}{ Komponen Pembiayaan } & $\mathbf{2 0 1 6}$ & $\mathbf{2 0 1 7}$ & $\mathbf{2 0 2 0}$ & $\mathbf{2 0 2 5}$ & $\mathbf{2 0 3 0}$ \\
\hline 1 & $\begin{array}{l}\text { Biaya Pengumpulan Sampah } \\
\text { (Rp/thn) }\end{array}$ & $\begin{array}{c}34.160 .74 \\
2\end{array}$ & 75.231 .163 & $\begin{array}{c}243.638 .61 \\
4\end{array}$ & 434.844 .130 & 693.072 .079 \\
\hline 2 & $\begin{array}{l}\text { Biaya Pengolahan Sampah di } \\
\text { TPS 3R (Rp/thn) }\end{array}$ & 525.121 & 2.186 .649 & 72.540 .174 & 212.292 .893 & 337.748 .565 \\
\hline 3 & $\begin{array}{l}\text { Biaya Pengangkutan dari } \\
\text { TPS 3R ke TPA (Rp/hari) }\end{array}$ & $\begin{array}{c}19.523 .22 \\
2\end{array}$ & 41.522 .902 & $\begin{array}{c}110.377 .74 \\
7\end{array}$ & 165.318 .175 & 249.279 .575 \\
\hline 4 & $\begin{array}{l}\text { Biaya Pengangkutan sampah } \\
\text { komersil ke TPS 3R } \\
\text { (Rp/hari) }\end{array}$ & 852.760 & 1.952 .007 & 5.076 .772 & 10.087 .371 & 19.644 .391 \\
\hline 5 & $\begin{array}{l}\text { Biaya Pengangkutan sampah } \\
\text { pasar ke TPS 3R (Rp/hari) }\end{array}$ & 5.363 .414 & 12.277 .095 & 31.930 .226 & 63.444 .254 & 123.552 .880 \\
\hline 6 & $\begin{array}{l}\text { Biaya Pengolahan di TPA } \\
\text { (Rp/thn) }\end{array}$ & $\begin{array}{c}28.464 .22 \\
3\end{array}$ & 63.224 .103 & $\begin{array}{c}166.962 .76 \\
6\end{array}$ & 281.670 .425 & 492.327 .422 \\
\hline & \multicolumn{1}{|c|}{ Jumlah } & $\begin{array}{c}88.889 .48 \\
2\end{array}$ & $\begin{array}{c}196.393 .91 \\
9\end{array}$ & $\begin{array}{c}630.526 .30 \\
0\end{array}$ & $\begin{array}{c}1.167 .657 .2 \\
48\end{array}$ & $\begin{array}{c}1.915 .624 .9 \\
12\end{array}$ \\
\hline
\end{tabular}

Tabel 12. Estimasi Tarif Retribusi Sampah Per KK Per Bulan

\begin{tabular}{|c|l|c|c|c|c|c|c|}
\hline $\begin{array}{c}\text { No } \\
\cdot\end{array}$ & \multicolumn{1}{|c|}{$\begin{array}{c}\text { Komponen } \\
\text { Pembiayaan }\end{array}$} & $\mathbf{2 0 1 6}$ & $\mathbf{2 0 1 7}$ & $\mathbf{2 0 2 0}$ & $\mathbf{2 0 2 1}$ & $\mathbf{2 0 2 5}$ & $\mathbf{2 0 3 0}$ \\
\hline 1 & $\begin{array}{l}\text { Total Biaya } \\
\text { OP/tahun (Rp) }\end{array}$ & $\begin{array}{c}88.889 .4 \\
82\end{array}$ & $\begin{array}{c}196.393 .9 \\
19\end{array}$ & $\begin{array}{c}630.526 .3 \\
00\end{array}$ & $\begin{array}{c}743.955 .6 \\
89\end{array}$ & $\begin{array}{c}1.167 .657 .2 \\
48\end{array}$ & $\begin{array}{c}1.915 .624 .9 \\
12\end{array}$ \\
\hline 2 & $\begin{array}{l}\text { Total Biaya OP/hr } \\
\text { (Rp) }\end{array}$ & 246.915 & 545.539 & 1.751 .462 & 2.066 .544 & 3.243 .492 & 5.321 .180 \\
\hline 3 & $\begin{array}{l}\text { Beban Pelayanan } \\
\text { /hr (ton) }\end{array}$ & 1,73 & 3,84 & 9,19 & 10,69 & 16,10 & 28,03 \\
\hline 4 & $\begin{array}{l}\text { Satuan Biaya } \\
\text { pelayanan/ton } \\
\text { (Rp) }\end{array}$ & 142.889 & 142.056 & 190.682 & 193.275 & 201.520 & 189.818 \\
\hline 5 & $\begin{array}{l}\text { Timbulan sampah } \\
\text { /org/hr (ton) }\end{array}$ & 0,000123 & 0,000123 & 0,000123 & 0,000123 & 0,000123 & 0,000123 \\
\hline 6 & $\begin{array}{l}\text { Biaya Pelayanan } \\
\text { Sampah/org/hr } \\
\text { (Rp) }\end{array}$ & 17,58 & 17,47 & 23,45 & 23,77 & 24,79 & 23,35 \\
\hline 7 & $\begin{array}{l}\text { Biaya Pelayanan } \\
\text { Sampah/KK/hr } \\
\text { (Rp) (1 kk =5 org) }\end{array}$ & 105,45 & 104,84 & 140,72 & 142,64 & 148,72 & 140,09 \\
\hline \multicolumn{2}{|l|}{$\begin{array}{l}\text { Retribusi Sampah } \\
\text { (KK/Bulan) }\end{array}$} & 3.164 & 3.145 & 4.222 & 4.279 & 4.462 & 4.203 \\
\hline
\end{tabular}

Dalam prosedur atau mekanisme penarikan retribusi rumah tinggal, direkomendasikan mekanisme pembayaran untuk rumah tinggal adalah :

1) Setiap kepala keluarga yang mendelegasikan pengelolaan sampah kepada petugas swakelola RT/RW atau petugas swasta, dikenakan wajib retribusi.

2) Besarnya retribusi yang harus dibayarkan meliputi : biaya pengumpulan dari rumah ke TPS dan sekaligus biaya dari TPS ke TPA. Biaya dari rumah ke TPS ditetapkan secara musyawarah, sedangkan biaya dari TPS ke TPA mengikuti Perda yang berlaku.

3) Selanjutnya petugas RT/RW atau pengelola swasta menyerahkan retribusi yang hanya meliputi biaya pengelolaan dari TPS ke TPA (sesuai Perda) kepada Badan Pengelola Lingkungan Hidup (BPLH) dan seterusnya diserahkan kepada Kas Daerah. 


\section{KESIMPULAN DAN REKOMENDASI}

Berdasarkan hasil inventarisasi dan analisis data yang telah dilakukan terkait Pengelolaan Sampah Kabupaten Mesuji didapatkan beberapa kesimpulan dan rekomendasi antara lain :

1) Sampah perumahan Kabupaten Mesuji merupakan penyumbang terbesar dari timbulan sampah Kabupaten Mesuji. Persentase sampah perumahan di Kabupaten Mesuji adalah sebesar 72,35\% dari jumlah total timbulan sampah Kabupaten Mesuji.

2) Jumlah timbulan sampah yang ada di Kabupaten Mesuji menurut hasil perhitungan adalah sebesar 33,03 ton/hari, namun jumlah sampah yang terangkut dan masuk ke TPA Kabupaten Mesuji adalah 2,31 ton/hari.

3) Cakupan layanan persampahan di Kabupaten Mesuji hanya meliputi kawasan pasar dan perkantoran.

4) Pengelolaan sampah rumah tangga di Kabupaten Mesuji masih menerapkan pengelolaan secara individu, yaitu dengan cara ditimbun atau dibakar.

5) Dalam pelaksanaan teknisnya, pengelolaan sampah di Kabupaten Mesuji melalui Badan Pengelolaan Lingkungan Hidup memiliki sarana persampahan dengan rincian :

- Alat pewadahan sampah individual berupa tong sampah sebanyak 200 Unit dan Kontainer kapasitas 6 m3 50 Unit.

- Alat pengumpulan sampah yang terdiri dari Motor sampah 7.

- Stasiun transfer berupa kontainer sebanyak 6 unit.

- Alat pengangkutan sampah yang terdiri dari Dump Truck 1 Unit.

6) Tempat pemrosesan Akhir sampah di Kabupaten Mesuji terletak di TPA Margo Rahayu. Dari hasil perhitungan kapasitas daya tampung TPA, TPA Margo Rahayu diprediksikan memiliki total daya tampung sebesar $29.520 \mathrm{~m} 2$ yang berarti bahwa TPA Margo Rahayu belum mengalami kelebihan muatan (over load).

7) Pelaksanaan pengelolaan sampah dibagi menjadi dua kategori yaitu pengelolaan sampah perkotaan dan pengelolaan sampah pedesaan.

8) Pelaksanaan pengelolaan sampah yang dilakukan sesuai dengan tata cara penanganan sampah perkotaan berada di Kecamatan Way Serdang dan Kecamatan Mesuji.

9) Pelaksanaan pengelolaan sampah pedesaan yang dilakukan dengan tata cara penanganan sampah pedesaab berada di Kecamatan Simpang Pematang, Kecamata Panca Jaya, Kecamatan Tanjung Raya, Kecamatan Mesuji Timur dan Kecamatan Rawajitu Utara.

10) Dalam tahapan pelaksanaannya, telah dibagi tahapan pelayanan sesuai dengan zona prioritas yang telah dibagi menjadi tiga wilayah pelayanan prioritas, antara lain :

- Wilayah pelayanan prioritas 1 : Kecamatan Way Serdang Dan kecamatan Mesuji.

- Wilayah pelayanan prioritas 2 : Kecamatan Simpang Pematang, Kecamatan Panca Jaya dan Kecamatan Tanjung Raya.

- Wilayah pelayanan prioritas 3 : Kecamatan Mesuji Timur dan Kecamatan Rawajitu Utara.

11) Untuk pengelolaan sampah perkotaan, semua sampah dari suber sampah dikumpulkan ke TPS 3R yang direncanakan pada masing - masing kelurahan untuk dioalah kemudian diangkut residunya saja ke TPA.

12) Untuk sampah pedesaan, hanya sampah pasar, komersil dan institusi yang diangkut ke TPS 3R untuk diolah secara komunal, sedangkan sampah pemukiman ditangani pada sumbernya atau secara individual.

13) Dalam perencanaan pelaksanaan teknis pengelolaan sampah Kabupaten Mesuji dengan umur rencana teknis adalah 15 tahun ke depan, didapatkan kebutuhan sarana dan prasarana sebagai berikut :

a) Alat Pewadahan

- Alat pewadahan sampah perumahan berupa wadah sampah portable seperti plastik, keranjang bambu atau karung yang diletakkan pada salah satu susdut rumah untuk 
memudahkan

penanganan

selanjutnya.

- Kontainer sampah pasar.

- Wadah sampah terpilah untuk smapah institusi dan komersil.

b) Alat Pengumpulan

- Alat pengumpulan sampah perumahan pada wilayah perkotaan yang terdiri dari motor sampah kapasitas 1,5 m3 dengan ritasi 2 kali/hari.

- Alat pengumpulan sampah pasar, komersil dan institusi pada wilayah pedesaan yang terdiri dari mobil pick up kapasitas $3 \mathrm{~m} 3$ dengan ritasi 2 kali/hari.

c) Tempat Pengolahan Sampah

Tempat Pengolahan Sampah 3R yang direncanakan pada masing - masing Kecamatan merupakan pengolahan yang terdiri dari pengomposan dan pemilahan. Dari tempat pengolahan ini dihasilkan residu yang akan dibawa ke TPA pada masing - masing zona.

d) Alat Pengangkutan

- Alat pengakutan sampah pasar, komersil dan institusi pada wilayah perkotaan ke TPS 3R berupa truk arm roll kapasitas $8 \mathrm{~m} 3$ dengan ritasi 2 kali/hari.

- Alat pengangkutan residu dari TPS 3R untuk wilyah perkotaan menggunakan arm roll kapasitas 8 m3 dengan ritasi 2 kali/hari.

- Alat pengangkutan residu dari TPS 3R untuk wilyah pedesaan menggunakan arm roll kapasitas 8 m3 dengan ritasi 2 kali/hari.

e) Perlu adanya penambahan dan peremajaan truk arm roll sebagai alat pengangkutan sampah di Kabaupaten Mesuji.

f) TPS 3R diarahkan memiliki lahan komposting untuk reduksi sampah, namun didalam analisis didapatkan tidak semua TPS mempunyai lahan sehingga luasan komposting menyesuaikan kapasitas lahan masingmasing TPS dengan dibantu komposting skala individu.

14) Dari hasil perhitungan, biaya pengelolaan sampah dari TPS ke TPA adalah Rp. 587.028.141,-/m3/tahun. Besaran perkiraan kebutuhan total biaya operasional pengelolaan sampah ini yang digunakan sebagai dasar untuk menentukan retribusi sampah.

15) Perhitungan besaran retribusi sampah didasarkan atas biaya operasional sampah dan biaya pelayanan sampah, sehingga didapat nilai retribusi untuk masing masing kepala keluarga. Besarana nilai retribusi yang harus dikeluarkan oleh masing - masing kepala keluarga per bulan adalah Rp. 4.222,- pada tahun 2020 , Rp. 4.462,- pada tahun 2025 dan Rp. 4.203,- pada tahun 2030.

\section{REFERENSI}

[1] Damanhuri, Padmi. 2010. Pengelolaan Sampah. Diktat Kuliah Teknik Lingkungan ITB. Bandung.

[2] _ 2011. Master Plan Peersampahan Kabupaten Mesuji. Dinas PU Kabupaten Mesuji. Mesuji.

[3] _ _ 2012. Master Kebijakan Dan Strategi Nasional Pengelolaan Sampah Rumah Tngga Dan Sampah Sejenis Rumah Tangga. Peraturan Presiden Republik Indonesia No. 81 Tahun 2012. Jakarta.

[4] _.. Standar Nasional Indonesia (SNI) 192454-2002. Tata Cara Teknik Operasional Pengelolaan Sampah Perkotaan.

[5] __... Standar Nasional Indonesia (SNI) 193964-1994. Metode pengambilan Dan Pengukuran Contoh Timbulan Dan Komposisi Sampah Perkotaan. 